\title{
High Surface Area Functionalized Carbon Briquettes: A Novel Adsorbent for Contaminants from Water
}

\author{
Luiz C.M. Costa ${ }^{a}$, Maria Helena Araujo ${ }^{a}, K_{\text {Krim Sapag }}^{b}$, Maria F. Sardella ${ }^{c}, H_{u g o}$ Silva ${ }^{c}$, \\ Ana C. Deiana ${ }^{*, c}$ and Rochel M. Lago ${ }^{*, a}$ \\ ${ }^{a}$ Departamento de Química, Universidade Federal de Minas Gerais, 31270-901 Belo Horizonte - MG, Brazil \\ ${ }^{b}$ Departamento de Física, Universidad Nacional de San Luis, San Luis, Argentina \\ ${ }^{c}$ Instituto de Ingeniería Quimica, Universidad Nacional de San Juan, San Juan, Argentina
}

\begin{abstract}
Neste trabalho, as vantagens de carbonos funcionalizados com alta área superficial e a forma especial de briquete foram combinadas para a produção de um novo adsorvente de metais. Análises BET, TG, IR, sítios ácidos e EDS sugerem que a funcionalização com $\mathrm{HNO}_{3}$ ocorre por todo o corpo do briquete. Foram estudadas também as isotermas e as cinéticas de adsorção de $\mathrm{Cr}^{3+}, \mathrm{Zn}^{2+}$ e do corante azul de metileno.
\end{abstract}

In this work, the advantages of special briquette shape and high surface area functionalized carbon were combined to produce a novel adsorbent for metals. BET, TG, IR, acid site and EDS analyses suggest that the functionalization with $\mathrm{HNO}_{3}$ and metal adsorption takes place throughout the briquette body. The adsorption isotherms and kinetics have been studied for $\mathrm{Cr}^{3+}, \mathrm{Zn}^{2+}$ and the dye methylene blue.

Keywords: briquettes, activated carbon, functionalization, adsorption

\section{Introduction}

Activated carbon shaped as briquettes offers several advantages over powder and granular carbons, especially in industrial and environmental applications where the manipulation and use of fine powders can be complicated..$^{1-8}$ In this work it is investigated for the first time the carbon surface modification by functionalization to produce special adsorbents based on activated carbon briquettes. This chemical modification can tailor the adsorbents by combining the advantages of a briquette shape with the presence of functional surface groups for special applications.

Herein, we show that carbon briquettes can be functionalized with concentrated $\mathrm{HNO}_{3}$ generating acidic groups, not only on the external surface of the briquette but also in the most internal layers of the carbon body. The functionalization strongly improves the adsorption of cationic species, such as $\mathrm{Zn}^{2+}, \mathrm{Cr}^{3+}$ and of the dye methylene blue, from aqueous medium with the adsorbed species homogeneously distributed throughout the briquette.

*e-mails: rochel@ufmg.br ; deiana@unsj.edu.ar

\section{Experimental}

The briquettes (ca. $1 \mathrm{~g}, 10 \mathrm{~mm}$ diameter x $13 \mathrm{~mm}$ length) were prepared from Eucalyptus camaldulensis Dehn wood (ca. $1 \mathrm{wt} \%$ ash, $11 \mathrm{wt} \%$ moisture, $69 \mathrm{wt} \%$ volatiles and $19 \mathrm{wt} \%$ fixed carbon) and rice husk ( $c a .17$ $\mathrm{wt} \%$ ash, $10 \mathrm{wt} \%$ moisture, $63 \mathrm{wt} \%$ volatiles and $10 \mathrm{wt} \%$ fixed carbon) pyrolyzed at $500{ }^{\circ} \mathrm{C}$ under $\mathrm{N}_{2}$ atmosphere for $4 \mathrm{~h}$. Concentrated grape must with density of $1.35 \mathrm{~g}$ $\mathrm{mL}^{-1}$ and sugar (fructose and glucose) content of $860 \mathrm{~g}$ $\mathrm{L}^{-1}$ was used as binder to prepare the briquettes (binder:char weight ratio of 1:4) in a mould held in a hydraulic press at $1,400 \mathrm{~kg} \mathrm{~cm}^{-2}$. The briquettes were thermally treated at $15{ }^{\circ} \mathrm{C} \mathrm{min}^{-1}$ up to $880{ }^{\circ} \mathrm{C}$ under $\mathrm{N}_{2}$ flow and activated with steam $\left(1.7 \mathrm{~g}_{\mathrm{H} 2 \mathrm{O}} \mathrm{g}_{\text {carbon }}{ }^{-1} \mathrm{~h}^{-1}\right)$ for $105 \mathrm{~min}$. The briquettes showed high mechanical strength with impact resistance index (IRI) ${ }^{9}$ of 1503 . The carbon samples were analyzed by BET (Autossorb 1 Quantachrome), TG (Shimadzu TGA 50H), IR (Perkin Elmer IR), EDS (energy dispersive and X-ray fluorescence spectroscopy in a scanning electron microscope Jeol JXA8900RL, Rigaku, Geigerflex 2037). Details of the preparation and characterization of these briquettes have 
been published elsewhere. ${ }^{8}$ The functionalization of the carbon briquettes was carried out with $\mathrm{HNO}_{3}$ (conc) under reflux for $60 \mathrm{~min}$. The adsorption isotherms were obtained after $24 \mathrm{~h}$ adsorption equilibrium of $20 \mathrm{mg}$ carbon with solutions $\left(20 \mathrm{~mL}, 28 \pm 2{ }^{\circ} \mathrm{C}\right)$ of the cationic species dye methylene blue (measured spectrophotometrically at 533 $\mathrm{nm}$ ), $\mathrm{Cr}^{3+}$ or $\mathrm{Zn}^{2+}$ (measured by AAS, Carls Zeiss Jena). The adsorption kinetics were studied using one briquette (intact or ground) in $100 \mathrm{~mL}$ solution of methylene blue (140 $\left.\mathrm{mg} \mathrm{L}^{-1}\right)$ or $\mathrm{Cr}^{3+}\left(200 \mathrm{mg} \mathrm{L}^{-1}\right)$ at $28 \pm 2{ }^{\circ} \mathrm{C}$ under stirring. The briquettes division in layers was carefully carried out with the aid of a blade to produce an outer $(c a .1 \mathrm{~mm}$ thick and $0.33 \mathrm{~g}$ ), a middle ( $c a .1 .5 \mathrm{~mm}, 0.33 \mathrm{~g}$ ) and an inner layer (ca. $2.5 \mathrm{~mm}, 0.33 \mathrm{~g}$ ).

\section{Results and Discussion}

The high surface area briquettes for application as adsorbents have been prepared by a careful procedure involving steps of chars production, binder addition, press moulding and thermal activation carefully established in a previous work. ${ }^{8}$ Another important feature of these briquettes is that they are produced from low cost agricultural by-products, i.e. eucalyptus waste, rice husks and grape most, available in different areas of Brazil and Argentine.

The carbon functionalization was carried out by the controlled oxidation with concentrated nitric acid. ${ }^{10,11}$ In order to obtain an analytical depth profile the briquette bodies were separated into three layers, i.e. outer, middle and inner, as shown in Figure 1.

The different layers of the functionalized briquettes, were analyzed by IR, TG, BET and acid titration. The IR spectroscopic analyses of the different layers clearly showed the presence of strong bands at $c a .3440$ and 1720 $\mathrm{cm}^{-1}$ characteristic of $\mathrm{COOH}$ groups formed by the oxidation with $\mathrm{HNO}_{3}$, and bands located at $c a .1595 \mathrm{~cm}^{-1}$ likely related to $\mathrm{NO}_{2}$ groups produced by the nitration of the carbon. These results agree with a large number of studies which show that the functionalization of activated carbon with concentrated nitric acid produces mainly surface carboxylic acid groups, $-\mathrm{COOH}$, and $-\mathrm{OH}$ and $-\mathrm{NO}_{2}$ in less extension. ${ }^{10,11} \mathrm{TG}$ analysis of the original briquette does not show any significant weight loss up to $400{ }^{\circ} \mathrm{C}$. On the other hand, oxidized carbons showed from ca. 4 up to $20 \%$ weight losses in the temperature range 120-400 ${ }^{\circ} \mathrm{C}$ due to the decomposition of the $\mathrm{COOH}$ and $-\mathrm{NO}_{2}$ groups to produce $\mathrm{CO}_{2}$ and $\mathrm{NO}_{2}$. The acid site concentrations determined by titration ${ }^{12}$ in the different layers of the briquettes treated with concentrated $\mathrm{HNO}_{3}$ are shown in Figure 1 and Table 1.

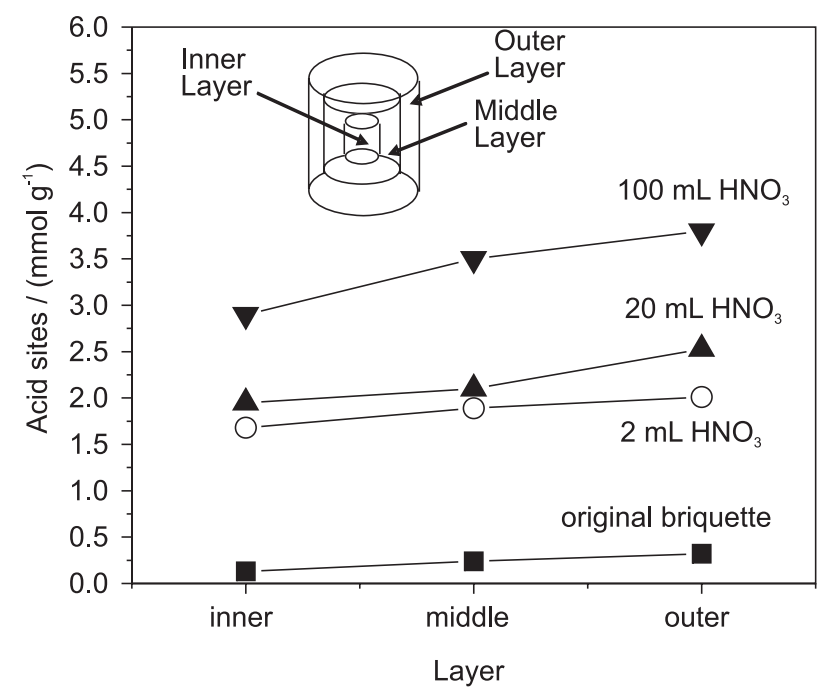

Figure 1. Effect of the amount of $\mathrm{HNO}_{3}$ used on the concentration of acidic sites in the different briquette layers (60 min reaction under reflux at $120{ }^{\circ} \mathrm{C}$ ).

It can be observed that the outer layer of the original briquette shows approximately $0.32 \mathrm{mmol} \mathrm{g}^{-1}$ acid sites which decrease to 0.24 and $0.13 \mathrm{mmol} \mathrm{g}^{-1}$ for the middle and inner layers, respectively. It is also observed for the

Table 1. Acid site concentration and BET surface areas for the different layers of briquettes treated with different volumes of $\mathrm{HNO}_{3}$ per $\mathrm{g}_{\text {briquette }}$ at $120{ }^{\circ} \mathrm{C}$ for $60 \mathrm{~min}$

\begin{tabular}{lcccc}
\hline \multicolumn{1}{c}{ Briquette } & Layer & Acid sites $\left(\mathrm{mmol} \mathrm{g}^{-1}\right)$ & Surface area $\left(\mathrm{m}^{2} \mathrm{~g}^{-1}\right)$ & Microporous area $\left(\mathrm{m}^{2} \mathrm{~g}^{-1}\right)$ \\
\hline Original briquette & Outer & 0.32 & 410 & 297 \\
& Middle & 0.24 & 373 & 289 \\
Treated with $2 \mathrm{~mL} \mathrm{HNO}_{3} / \mathrm{g}_{\text {briquete }}$ & Inner & 0.13 & 391 & 274 \\
& Outer & 2.01 & 408 & 284 \\
Treated with 20mL $\mathrm{HNO}_{3} / \mathrm{g}_{\text {briquette }}$ & Middle & 1.89 & 397 & 273 \\
& Inner & 1.68 & 418 & 272 \\
Treated with 100mL $\mathrm{HNO}_{3} / \mathrm{g}_{\text {briquette }}$ & Outer & 2.53 & 437 & 342 \\
& Middle & 2.10 & 414 & 342 \\
& Inner & 1.95 & 458 & 379 \\
& Mider & 3.93 & 486 & 465 \\
\end{tabular}


outer layer a slightly higher BET surface area of $410 \mathrm{~m}^{2} \mathrm{~g}^{-1}$ compared to the middle and inner layers. When the briquettes are treated with $\mathrm{HNO}_{3}$ at the ratio of $2 \mathrm{~mL}$ acid/ $\mathrm{g}_{\text {briquette }}$ a large increase in the acid sites to 2.01, 1.89 and $1.68 \mathrm{mmol} \mathrm{g}^{-1}$ is produced in the outer, middle and inner layers, respectively. Under reflux with $\mathrm{HNO}_{3}$ at $20 \mathrm{~mL}$ acid/ $\mathrm{g}_{\text {briquette }}$ the acid sites further increased and a significant increase in the surface area is observed. The data presented in Table 1 suggest that this increase in surface area is related to an increase in the microporosity of the material. If the reaction is carried out with $100 \mathrm{~mL} \mathrm{HNO}_{3} / \mathrm{g}_{\text {briquette }}$ for 60 min under reflux, a strong increase in the acid site concentration to approximately $4 \mathrm{mmol} \mathrm{g}^{-1}$ is produced (Figure 1). However, the briquette becomes very fragile with low mechanical resistance.

In order to investigate the effect of the functional groups on adsorption processes, experiments with $\mathrm{Cr}^{3+}{ }_{(\mathrm{aq})}, \mathrm{Zn}^{2+}{ }_{\text {(aq) }}$ and the dye methylene blue ${ }_{(a q)}$, a positively charged organic molecule, were carried out. The adsorption isotherms of the dye methylene blue and $\mathrm{Cr}^{3+}{ }_{(\text {aq })}$ for the original and functionalized briquettes are shown in Figure 2.

It can be observed that the original briquette adsorbs a maximum of approximately $140 \mathrm{mg}$ dye $\mathrm{g}^{-1}$ adsorbent. On
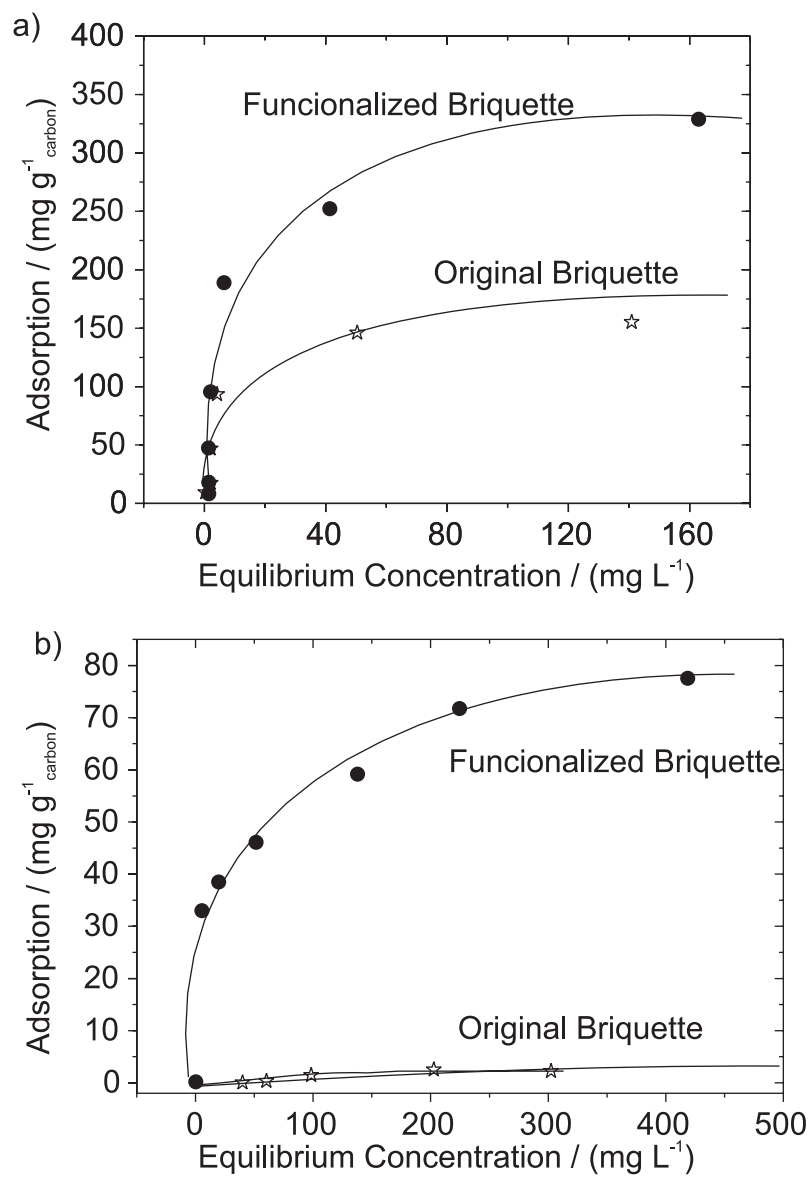

Figure 2. Adsorption isotherms of (a) methylene blue dye and (b) $\mathrm{Cr}^{3+}$ on the original and functionalized briquettes. the other hand, upon functionalization, the adsorption capacity increases up to $330 \mathrm{mg} \mathrm{g}^{-1}$. A more significant effect is observed for the adsorption of $\mathrm{Cr}^{3+}$ which increases from approximately $1 \mathrm{mg} \mathrm{g}^{-1}$ for the original briquette up to $78 \mathrm{mg} \mathrm{g}^{-1}$ for the functionalized carbon. These results suggest that the presence of the surface carboxylic groups strongly improve the adsorption of the cationic species from the aqueous medium.

In order to investigate if a preferential adsorption on the more external part of the briquette occurs or if the metal can diffuse and adsorb into the briquette body, EDS analyses of $\mathrm{Zn}^{2+}$ adsorbed briquette were carried out. The adsorption experiments with $\mathrm{Zn}^{2+}{ }_{\text {(aq) }}$ were carried out by exposing the functionalized briquettes to the metal aqueous solution for $24 \mathrm{~h}$ at $28 \pm 2{ }^{\circ} \mathrm{C}$. After drying, the briquette was cut transversally and analyzed from the centre to the border by EDS/SEM with approximately 6 spectra $\mathrm{mm}^{-1}$. The EDS spectra showed signals related to the elements $\mathrm{Si}, \mathrm{S}, \mathrm{Ca}, \mathrm{Al}, \mathrm{K}$ and $\mathrm{Mg}$, all originated from the precursors used and two strong signals at 8.6 and $1.6 \mathrm{keV}$ related to $\mathrm{Zn}$. The relative areas of the $\mathrm{Zn}$ signal peak for the spectra obtained at different points of the briquette are shown in Figure 3.

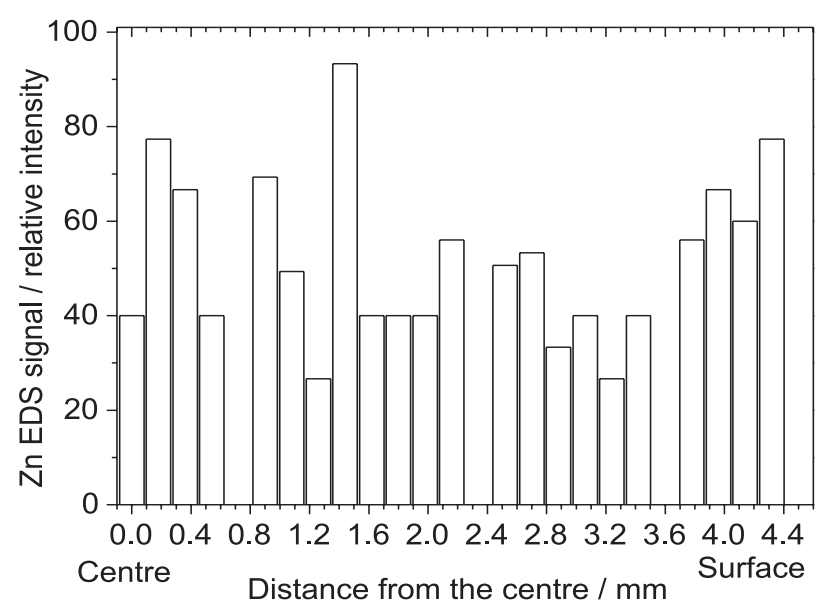

Figure 3. Relative intensities of the EDS $\mathrm{Zn}$ signals at $8.6 \mathrm{keV}$ from the centre to the border of the functionalized briquette exposed to a $\mathrm{Zn}^{2+}$ solution.

It can be observed that the Zn EDS signals from the centre to the border of the briquette showed similar relative intensities, suggesting that $\mathrm{Zn}^{2+}$ does not adsorb preferentially on the more external surface of the briquette. These results suggest that the briquette possesses a porous structure large enough to allow facile diffusion of the hydrate $\mathrm{Zn}^{2+}$ species and its homogeneous adsorption throughout the briquette body.

It was also investigated if the adsorption on the briquette was limited by diffusion of the adsorbate into the inner part of the briquette body. The adsorption kinetics 

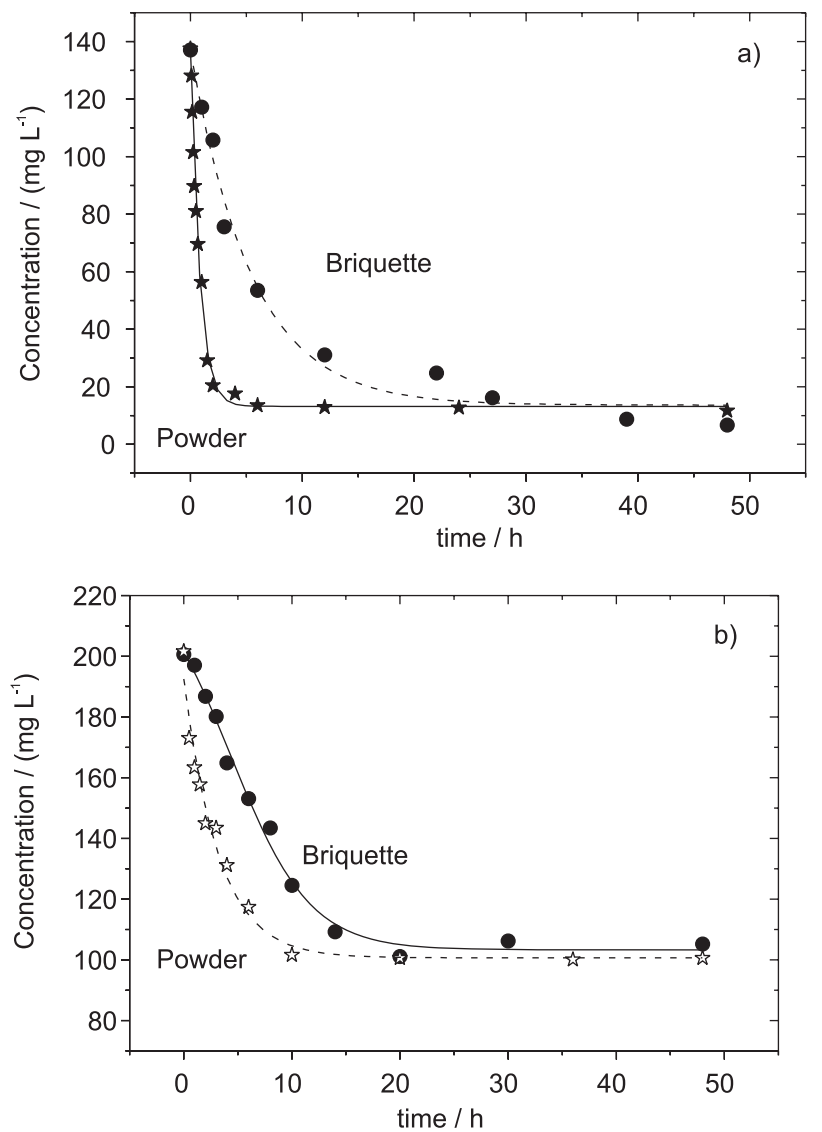

Figure 4. Adsorption kinetics of (a) methylene blue and (b) $\mathrm{Cr}^{3+}$ on the functionalized carbon as a briquette and as a powder.

of methylene blue and $\mathrm{Cr}^{3+}$ on the functionalized carbon as a briquette and as a powder were compared. The results are displayed in Figure 4.

It can be observed that the adsorption of the dye onto powder functionalized carbon takes place with a first order dependent rate constant $\boldsymbol{k}_{\text {ads }}$ of $1.5 \times 10^{-1} \mathrm{~h}^{-1}$ whereas the adsorption onto the briquette is a much slower process with $\boldsymbol{k}_{\text {ads }}$ of $1.6 \times 10^{-2} \mathrm{~h}^{-1}$. On the other hand, for the adsorption kinetics of $\mathrm{Cr}^{3+}$ on carbon powder a $\boldsymbol{k}_{\text {ads }}$ of $6.8 \times 10^{-2} \mathrm{~h}^{-1}$ was observed whereas the adsorption onto the briquette was a slightly slower process with rate constant of $4.5 \times 10^{-2} \mathrm{~h}^{-1}$. This suggests that in the case of the relative large organic molecule methylene blue the diffusion significantly affects the rate of the adsorption process whereas the adsorption of the smaller metal cation $\mathrm{Cr}^{3+}$ is much less affected by diffusion processes.
In conclusion, the functionalization of activated carbon briquettes with $\mathrm{HNO}_{3}$ can be carried out homogeneously throughout the briquette body, suggesting that the $\mathrm{HNO}_{3}$ molecule can penetrate the porous structure to oxidize the carbon surface to produce mainly carboxylic groups in the most internal surface of the briquettes. The presence of these carboxylic groups strongly promote the adsorption of $\mathrm{Zn}^{2+}$, $\mathrm{Cr}^{3+}$ and of the dye methylene blue, which are homogeneously adsorbed throughout the briquette body. Adsorption kinetic measurements suggest that the adsorption of metallic cations onto the briquette is not seriously controlled by diffusion whereas for large organic molecules a significant diffusion limitation is observed.

\section{Acknowledgements}

The authors wish to thank FAPEMIG, CNPq, PRPq/ UFMG and CAPES-SECYT and the Laboratório de Microscopia Eletronica, UFMG.

\section{References}

1. MacDowall, J.; US pat. 5,162,286 1992.

2. Yan, Z.Q.; McCue, J.; Tolles, E.; US pat. 5,538,932 1996.

3. Yamada, T.; Tsumuki, K.; US pat. 5,685,986 1997.

4. Rhys Jones, D.C. In Chemistry of Coal Utilization; Lowry H.H., ed., John Wiley \& Sons: New York ,1963, $2^{\text {nd }}$ supplementary volume.

5. Schinzel, W. In Chemistry of Coal Utilization; Lowry H.H., ed., John Wiley \& Sons: New York, 1981, $2^{\text {nd }}$ supplementary volume.

6. Taylor, J.W.; Fuel 1988, 67, 1945.

7. Clarke, D.E.; Marsh, H.; Fuel 1989, 68, 1031.

8. Deiana, A.C.; Granados, D.L.; Petkovic, L.M.; Sardella, M.F.; Silva, H.S.; Braz. J. Chem. Eng. 2004, 21, 585.

9. Rios, R.V.R.A.; Donnici, C.L.; Bento, J.S.; Pinto, D.; Lago, R.M.; Mat. Res. 2003, 6, 152.

10. Radovic, L.R.; Reinoso, F.R. In Chemistry and Physics of Carbon; Thrower, P.A., ed., Marcel Dekker: New York, 1997, vol. 25 .

11. Richards, S.R.; Fuel Proc. Technol. 1990, 25, 89.

12. Bohem, H.P.; Carbon 1994, 32, 759.

Received: April 22, 2005

Published on the web: July 27, 2005 